\title{
Neonatal care awareness among Bangladesh women
}

\begin{abstract}
Background: Mothers knowledge and practices shape the future of the new born. The child's early growth and development, both physical and behavioral, is largely influenced by his interactions with the important people who give him care.

Objective: The objective of this study was to assess awareness on neonatal care among women having one pregnancy resulting one viable young.

Methodology: It was a cross-sectional study conducted among purposively selected 107 women having one pregnancy resulting one viable young from two selected districts (Gazipur and Mymensingh) in Bangladesh. Pre-tested semi structured questionnaire was used for data collection. Face to face interview was conducted. Level of awareness was determined by pre-defined scoring.

Results: Mean \pm SD age of respondents was $21.56 \pm 3.77$ and $23.41 \pm 5.34$ in Gazipur and Mymensingh district respectively. About $81.30 \%, 13.08 \%$ and $5.60 \%$ respondents had poor, moderate and good awareness on newborn care respectively. About $82.24 \%, 14 \%$ and $3.73 \%$ respondents had poor, moderate and good awareness on neonatal physiological function respectively. Regarding umbilical cord care $62.61 \%, 28.97 \%$ and $8.41 \%$ respondents had poor, moderate and good awareness respectively. Poor awareness was more among who had education level below SSC and it was statistically significant $(\mathrm{P}<0.05)$. Poor awareness was prominent among housewives. Statistically significant association was found between occupation of respondents and awareness on newborn care.
\end{abstract}

Conclusion: It is concluded that awareness on neonatal health among mothers having one pregnancy was not satisfactory.

Keywords: neonatal care awareness, Bangladesh women
Volume 2 Issue 4 - 2015

\author{
Md Mahfuj Rana Shahin,' Md Monoarul \\ Haque, ${ }^{2}$ Golam Mainuddin,' Md Al Jahidi \\ Hasan Chowdhury,' Zabunnesa Suchi, ${ }^{3}$ Md \\ Zahid Hasan Khan ${ }^{4}$ \\ 'ASA University Bangladesh, Bangladesh \\ 2Bangladesh Stroke Association, Bangladesh \\ ${ }^{3}$ Bangladesh Institute of Thyroid Medicine \& Imaging Research, \\ Bangladesh \\ ${ }^{4}$ Northern University Bangladesh, Bangladesh
}

Correspondence: Md Monoarul Haque, Intern Fellow, USAID \& Research Coordinator, Bangladesh Stroke Association, Bangladesh, Tel +8801915839550,

Email monoarmunna@yahoo.com

Received: March 31, 2015 | Published: June 19, 2015

\section{Introduction}

Children are the future of any nation. It is well established that the welfare of a child and his future are totally dependent upon the care and attention bestowed upon him before and after birth. Care of the children had always traditionally been the forte of mothers irrespective of education, income and social class differences. The important task of motherhood is to fulfill physical, emotional, social, intellectual and moral needs of children. There is no doubt that a mother plays an important role in this regard. Available research studies reveals that mothers had average to poor knowledge on new born care. ${ }^{1,2} \mathrm{~A}$ descriptive study was conducted in South India among 100 postnatal mothers on knowledge and attitude towards neonatal care and the practices they follow. Findings of the study showed that knowledge of mothers was inadequate in areas of umbilical cord care, thermal care and vaccine preventable diseases. ${ }^{3}$ Thus the poor knowledge on part of mothers can lead to unsuccessful results in the field of care giving. There is scope for improvement by providing better care and health education for antenatal mothers. If the mothers are not acquainted with knowledge pertaining to dangers signs, hygienic practices, feeding, weaning, health and nutrition including growth and behavior of children, it might affect the rearing of their children. ${ }^{4}$ Thus the present study was undertaken to assess the level of awareness among mothers regarding newborn care.

\section{Methodology}

This was a cross-sectional study. This study was designed to grab more data in a short time, so that it can be used for assessing the level of awareness of the respondents. Data were collected from Gazipur and Mymensingh district in Bangladesh. This study was conducted for a period of four month started from may 2014 to August 2014. Study population was mothers having single child aged below 28 days. Almost 107 mothers were studied. Purposive sampling technique was used to collect data. Data were collected from the respondents through face-to-face interview. The questionnaires were used after verbal consent of the respondents and their voluntary participation was sought. Awareness level was determined by pre-defined scoring. Three categories were defined on the basis of the score obtained by each participant: poor $(<50 \%$ of the total score $)$; moderate $(50 \%$ $70 \%$ of the total score) and good ( $>70 \%$ of the total score). After data collection, data were sent to the researcher, which was sorted, scrutinized by the researcher and then data were analyzed by SPSS version 12.0 program. Initial ethical clearance was sought from the ethical review committee for conducting the study. Consent was taken from every individual. Confidentiality of the person and the information was maintained, observed and unauthorized persons did not access to the data. Each subject was assigned an identification number and these subject identifiers did not release outside the authorized person. 


\section{Results}

(Table 1-4).

Table I Socio-demographic characteristics $(n=107)$

\begin{tabular}{|c|c|c|}
\hline Age group (yrs) & Gazipur (\%) & Mymensingh (\%) \\
\hline $15-18$ & $\mathrm{II}(22)$ & II(I9.3) \\
\hline$|8-2|$ & $16(32)$ & $\mid 2(2 \mid .2)$ \\
\hline $21-24$ & |4(28) & $9(15.8)$ \\
\hline $24-27$ & $3(6)$ & $12(2 \mid .2)$ \\
\hline $27-30$ & $5(10)$ & $9(15.8)$ \\
\hline $30-33$ & $\mathrm{I}(2)$ & $0(0)$ \\
\hline $33-36$ & $0(0)$ & $3(5.3)$ \\
\hline $36-39$ & $0(0)$ & $\mathrm{I}(\mathrm{I} .8)$ \\
\hline Mean $\pm S D$ & $21.56 \pm 3.77$ & $23.4 I \pm 5.34$ \\
\hline \multicolumn{3}{|l|}{ Occupation } \\
\hline Housewife & $20(40.0)$ & $23(40.4)$ \\
\hline Service & $30(60.0)$ & $34(59.6)$ \\
\hline \multicolumn{3}{|l|}{ Education } \\
\hline Illiterate & $3(6)$ & $7.98(14)$ \\
\hline Primary & $12(24)$ & $13.68(24)$ \\
\hline $\begin{array}{l}\text { Secondary School Certificate } \\
\text { (SSC) }\end{array}$ & $12(24)$ & $14.02(24.60)$ \\
\hline $\begin{array}{l}\text { Higher Secondary Certificate } \\
\text { (HSC) }\end{array}$ & $14(28)$ & $12.02(21.10)$ \\
\hline Graduate & $6(12)$ & $7.01(12.30)$ \\
\hline Postgraduate & $3(6)$ & $1.99(3.5)$ \\
\hline \multicolumn{3}{|l|}{ Income in BDT } \\
\hline $1000-6000$ & $4(8)$ & $10.26(18)$ \\
\hline $6001-10000$ & $10(20)$ & $14.8(26)$ \\
\hline $10001-15000$ & $12(24)$ & $16.98(29.80)$ \\
\hline$|500|-20000$ & $9(18)$ & II(I9.30) \\
\hline $2000 I-25000$ & $15(30)$ & $3.99(7)$ \\
\hline Total & $50(100)$ & $57(100)$ \\
\hline
\end{tabular}

Mean \pm SD age was $21.56 \pm 3.77$ and $23.4 I \pm 5.34$ in Gazipur and Mymensingh respectively. More than half of respondents were service holder (Government, Non-government and private job) in both districts. About $24 \%$ respondents from Gazipur and Mymensingh district passed primary school and nearly equal scenario was seen in case of Secondary School Certificate (SSC). In Higher Secondary Certificate (HSC) level Gazipur and Mymensingh was 28\% and $21.10 \%$ respectively. About 30\% respondents's monthly income was 20000 25000 BDT in Gazipur district whereas in Mymensingh district it was 7\%.
Table 2 Distribution of respondents by awareness on newborn care

\begin{tabular}{lll}
\hline General information & Number & Percentage \\
\hline Poor Awareness & 87 & 81.3 \\
Moderate Awareness & 14 & 13.08 \\
Good Awareness & 6 & 5.6 \\
\hline
\end{tabular}

\begin{tabular}{lcl}
\hline Neonatal Physiological Function & \\
\hline Poor Awareness & 88 & 82.24 \\
Moderate Awareness & 15 & 14 \\
Good Awareness & 4 & 3.73 \\
\hline Breast Feeding & & \\
\hline Poor Awareness & 85 & 79.43 \\
Moderate Awareness & 20 & 18.69 \\
Good Awareness & 2 & 1.86 \\
\hline Umbilical Cord Care & & \\
\hline Poor Awareness & 67 & 62.61 \\
Moderate Awareness & 31 & 28.97 \\
Good Awareness & 9 & 8.41 \\
\hline Personal Hygiene & & \\
\hline Poor Awareness & 83 & 77.57 \\
Moderate Awareness & 17 & 15.88 \\
Good Awareness & 7 & 6.54 \\
\hline Mor & & \\
\hline
\end{tabular}

Maintenance of Neonatal Body Temperature

\begin{tabular}{lcc}
\hline Poor Awareness & 53 & 49.53 \\
Moderate Awareness & 34 & 31.77 \\
Good Awareness & 20 & 18.69 \\
\hline Newborn Care Practices & \\
\hline Poor Awareness & 31 & 28.97 \\
Moderate Awareness & 57 & 53.27 \\
Good Awareness & 19 & 17.75 \\
Total & 107 & 100 \\
\hline
\end{tabular}

Most of the respondents had poor awareness on general information on neonatal care, neonatal physiological function, breast feeding, umbilical cord care and personal hygiene. More than half of the respondents had poor awareness on maintenance of neonatal body temperature and moderate awareness on newborn care practices. 
Table 3 Association between education and awareness on newborn care

\begin{tabular}{|c|c|c|c|c|c|}
\hline \multirow{2}{*}{ Level of Education } & \multicolumn{2}{|c|}{ Awareness on newborn care } & \multirow{2}{*}{ Total } & \multirow{2}{*}{$\chi^{2}$} & \multirow{2}{*}{ P Value } \\
\hline & Poor Awareness N (\%) & Good Awareness N (\%) & & & \\
\hline Up to SSC & $47(43.92)$ & $10(9.34)$ & $57(53.26)$ & \multirow{2}{*}{26.37} & \multirow{2}{*}{0.006} \\
\hline$>$ SSC & $40(37.38)$ & $10(9.34)$ & $50(46.72)$ & & \\
\hline
\end{tabular}

Results were expressed as frequency percentage, $\chi 2$ test was performed and $\mathrm{P}<0.05$ was level of significance.

Poor awareness was more among who had education level below SSC and it was statistically significant $(P<0.05)$.

Table 4 Association between occupation and awareness on newborn care

\begin{tabular}{llllll}
\hline \multirow{2}{*}{ Occupation } & \multicolumn{2}{l}{ Awareness on newborn care } & Total & $\chi^{2}$ & P Value \\
\cline { 2 - 5 } & Poor Awareness N (\%) & Good Awareness N (\%) & & \\
\hline Housewife & $32(29.90)$ & $1 \mathrm{I}(10.28)$ & $43(40.18)$ & $16.8 \mathrm{I}$ & 0.01 \\
Service & $28(26.16)$ & $36(33.64)$ & $64(59.8 I)$ & \\
\hline
\end{tabular}

Results were expressed as frequency percentage, $\chi 2$ test was performed and $\mathrm{P}<0.05$ was level of significance.

Housewife had more poor awareness than service holder mother and it was significant statistically $(P<0.05)$.

\section{Discussion}

Cultural influences, competing pressures and perceptions of hereditary influences, together with a lack of contemporary neonatal health knowledge are the main factors affecting neonatal health knowledge and beliefs. Mothers knowledge, belief and practices help in formulation of more effective strategies to benefit neonates. The present study found mean $\pm \mathrm{SD}$ of age was $21.56 \pm 3.77$ and 23.41 \pm 5.34 in Gazipur and Mymensingh district respectively. Most of the respondents $(81.30 \%)$ had poor awareness on newborn care. Awareness on neonatal physiological function was poor. Regarding umbilical cord care $62.61 \%, 28.97 \%$ and $8.41 \%$ respondents had poor, moderate and good awareness. Poor awareness was more among who had education level below SSC and it was statistically significant. A study was done in India ${ }^{5,6}$ and showed that majority of mothers had excellent knowledge and practice about neonatal care which was dissimilar to our study. Different population may be the cause. The findings are supported by a survey study conducted in 2006 which revealed that mothers' knowledge and practices were within good and satisfactory average scores in most of the studied items related to neonatal care giving at home except breast feeding. ${ }^{7}$ Another study from Bangladesh in which 6150 data were drawn from the Bangladesh Demographic and Health Survey 2007, compared with mothers with no education those with secondary or higher levels were associated with clean cord care. ${ }^{8}$ The place of delivery, knowledge regarding newborn care was found to be associated with cord care P-value $<0.05$. After adjusting in logistic regression, knowledge regarding newborn care was again found to be associated with cord $(\mathrm{OR}=0.10$, $95 \% \mathrm{CI}=0.02-0.41$ ). A study from Nepal (1994 to 1996) identified that health education for postnatal mothers in poor communities had no impact on recommended practice such as cord care, infant feeding or immunization ${ }^{9}$ which is opposite to the findings of this study.

\section{Conclusion}

The study revealed that awareness on neonatal health among primipara mothers was not satisfactory. Most of the respondents had poor awareness on newborn care, neonatal physiological function and umbilical cord care. Significant association was found between education of respondents and awareness on newborn care.
Statistically significant association was found between occupation of respondents and awareness on newborn care. Finally a wide gap was found regarding awareness on neonatal health among mothers having young child. Effective health education programme can be constituted so that mother's awareness level on neonatal care will increase.

\section{Acknowledgements}

None.

\section{Conflict of interest}

The author declares no conflict of interest.

\section{References}

1. Fishbein EG, Burggraf E. Early Postpartum Discharge: How are mothers managing? J Obstet Gynecol Neonatal Nurs. 1998;27(2):142-148.

2. Senath U, Fernando DN, Vimpani G, et al. Factors associated with maternal knowledge of newborn care among hospital delivered mothers in Sri Lanka. Transactions of the Royal Society of Tropical Medicine and Hygiene. 2007;101(8):823-830.

3. Padiyath MA, Bhat VB, Ekambaram M. Knowledge attitude and practice of neonatal care among postnatal mothers. Curr Pediatr Res. 2010;14(2):147-157.

4. Jensen G. The well child's problems. USA: Year Book Medical Publishers; 1962. 312 p.

5. Roberts F. Review of pediatric nursing. USA: CV Mosby Publishing Company; 1978. 213 p.

6. Castalino F, Nayak BS, Dsouza A. Knowledge and Practices of Postnatal Mothers on Newborn Care In Tertiary Care Hospital of Udupi District. NUJHS. 2014;4(2):98-101.

7. Fowles RE, Horowitz JA. Clinical assessment of Mothering during Infancy. J Obstet Gynecol Neonatal Nurs. 2006;35(5):662-670.

8. Shahjahan M, Ahmed MR, Rahman MM, et al. Factors affecting newborn care practices in Bangladesh. Paediatr Perinat Epidemiol. 2012;26(1):13-18.

9. Bolam A, Manandhar DS, Shrestha P, et al. The effects of postnatal health education for mothers on infant care and family planning practices in Nepal: a randomized controlled trial. BMJ. 1998;316(7134):805-811. 